\title{
Structural vaccinology: structure-based design of influenza A virus hemagglutinin subtype-specific subunit vaccines
}

\author{
Chunling Xuan ${ }^{1,2}$, Yi Shi ${ }^{1}$, Jianxun $\mathbf{Q i}^{1}$, Wei Zhang ${ }^{1,2}$, Haixia Xiao ${ }^{4}$, George F. Gao ${ }^{1,2,3,4} \bowtie$ \\ ${ }^{1}$ CAS Key Laboratory of Pathogenic Microbiology and Immunology, Institute of Microbiology, Chinese Academy of Sciences, \\ Beijing 100101, China \\ 2 Graduate University, Chinese Academy of Sciences, Beijing 100049, China \\ ${ }^{3}$ Research Network of Immunity and Health (RNIH), Beijing Institutes of Life Science, Chinese Academy of Sciences, \\ Beijing 100101, China \\ ${ }^{4}$ Laboratory of Protein Engineering and Vaccines, Tianjin Institute of Industrial Biotechnology, Chinese Academy of Sciences, \\ Tianjin 300308, China \\ $\triangle$ Correspondence: gaof@im.ac.cn \\ Received December 1, 2011 Accepted December 10, 2011
}

\section{ABSTRACT}

There is a great need for new vaccine development against influenza $A$ viruses due to the drawbacks of traditional vaccines that are mainly prepared using embryonated eggs. The main component of the current split influenza $A$ virus vaccine is viral hemagglutinin (HA) which induces a strong antibody-mediated immune response. To develop a modern vaccine against influenza $A$ viruses, the current research has been focused on the universal vaccines targeting viral M2, NP and HA proteins. Crystallographic studies have shown that HA forms a trimer embedded on the viral envelope surface, and each monomer consists of a globular head (HA1) and a "rod-like" stalk region (HA2), the latter being more conserved among different HA subtypes and being the primary target for universal vaccines. In this study, we rationally designed the HA head based on the crystal structure of the 2009-pandemic influenza A (H1N1) virus $\mathrm{HA}$ as a model, tested its immunogenicity in mice, solved its crystal structure and further examined its immunological characteristics. The results show that the HA globular head can be easily prepared by in vitro refolding in an $E$. coli expression system, which maintains its intact structure and allows for the stimulation of a strong immune response. Together with recent reports on some similar HA globular head preparations we conclude that structure-based rational design of the HA globular head can be used for subtype-specific vaccines against influenza viruses.

KEYWORDS influenza virus, subunit vaccine, hemagglutinin, structure, design

\section{INTRODUCTION}

Influenza viruses, together with common cold viruses, are the most common human viral pathogens causing infections with various consequences, from pandemics to seasonal flu (Fields et al., 2007). The 2009 pandemic H1N1 swine-origin influenza A virus (S-OIV) was the first pandemic virus in the 21 st century, which reminds us of the serious human public health problems that can result from animal-borne influenza viruses (Yang et al., 2009; Neumann et al., 2009; Guan et al., 2010; Sun et al., 2010) Historically there have been three major pandemics, namely the $1918 \mathrm{H} 1 \mathrm{~N} 1$ pandemic (Spanish flu), 1957 H2N2 pandemic (Asian flu) and 1968 H3N2 pandemic (Hong Kong flu) (Kilbourne, 2006; Fields et al., 2007; Neumann et al., 2009). If Influenza A virus hits human beings with a pandemic, then it slows down, by gradual adaptation to the human host, leading to seasonal flu (Fields et al., 2007; Lipsitch et al., 2007). Efficient measures to prevent and control the influenza viruses are vaccination and therapeutic drugs (Belshe et al., 2000; Wood and Robertson, 2004; Das et al., 2010; Vavricka et al., 2011). Currently influenza virus vaccines are prepared by growing the virus in 
embryonated eggs followed by inactivation of the amplified virus being inactivated with formaldehyde (Furuya et al., 2010), the so called inactivated vaccines. The main component in the vaccine is the viral surface envelope glycoprotein, hemagglutinin (HA). Due to intrinsic characteristics of antigenic shift and antigenic drift of the influenza virus, yearly vaccinations are needed using the predicted epidemic virus strain as the immunogen source. An inaccurate prediction of the epidemic strain can lead to a complete failure or weak protection of the annual vaccination. The procedure of the vaccine preparation from embryonated eggs is tedious and the lack of enough egg resources to cover the whole population is worrisome. A shortage of enough vaccines would be detrimental during potential outbreaks of both the seasonal flu and any potential pandemics. Therefore the current research for influenza vaccine development focuses on: (1) universal vaccines to cover all-flu types and development of a single vaccination program for a long-lasting protection; and (2) versatile and quick vaccine preparation measures, including genetic engineering methods, to replace the methods using embryonated eggs.

Influenza A virus is an enveloped negative-stranded RNA virus with a segmented genome of 8 gene segments, which encode 11 proteins (Fields et al., 2007; Neumann et al., 2009; Das et al., 2010). There are three major envelope surface proteins, $\mathrm{HA}$, neuraminidase (NA) and $\mathrm{M} 2$, embedded on the virus membrane. HA is initially synthesized as a polypeptide of $\mathrm{HAO}$ and subsequently processed by cellular enzymes into two fragments of HA1 and HA2. HA mediates the virus fusion and entry by endocytosis through its binding to appropriate sialic acid containing receptors and is the major target for vaccine preparation. Based on serology, $\mathrm{HA}$ can be grouped into 16 subtypes, $\mathrm{H} 1$ to $\mathrm{H} 16$ (Fields et al., 2007; Neumann et al., 2009), which are mainly determined by HA1. Among them only three major subtypes infect human beings, namely $\mathrm{H} 1$, $\mathrm{H} 2$ and $\mathrm{H} 3$, with occasional sporadic infections of other subtypes, e.g. H5, H7 or H9 (Kurtz et al., 1996; Claas et al., 1998; Lin et al., 2000; Belser et al., 2007). Human infection of avian $\mathrm{H} 5 \mathrm{~N} 1$ subtype has been growing in the last decade and is considered a major potential threat for a future influenza pandemic (Claas et al., 1998; Subbarao et al., 1998; Tran et al., 2004; Beigel et al., 2005; Neumann et al., 2009). The first X-ray crystal structure of the HA was solved in early 1980's pioneered by Wilson, Skehel and Wiley (Wilson et al., 1981). Since then a dozen more three dimensional structures of HAs have been ever reported and the structures clearly show that HA forms an intact trimer (Skehel and Wiley, 2000; Gamblin et al., 2004; Stevens et al., 2006; Zhang et al., 2010). The HA monomer structure consists of a globular head formed by HA1 and a "rod-like" stalk region formed mainly by HA2 with some N-terminal portions of HA1. Antibodies targeting the stalk region have been found to induce a broad-spectrum neutralizing response against different virus strains, even different subtypes of influenza viruses (Ekiert et al., 2009; Bommakanti et al., 2010; Wang et al., 2010; Corti et al., 2011; Ekiert et al., 2011). Therefore this could be a target for development of universal vaccines. On the other hand, the globular head has an intact and presumably-stable structure and can be a good candidate for subtype-specific vaccine if a versatile preparation method can be developed.

In this study, we have designed three globular head HA1 constructs based on the HA crystal structure of the 2009pandemic influenza virus HA as a model (Zhang et al., 2010). The proteins are expressed in the prokaryotic $E$. coli system in inclusion bodies and subsequently refolded in vitro. Biochemical and immunological characterizations of these refolded proteins have been carried out which indicate that this is an efficient method for HA globular head preparation. The crystal structure of the globular head has also been solved, showing it is a stable protein with all the definedepitopes faithfully exposed as seen in the trimeric HA structure. Immunization of the protein in mice induces good protection against the homologous virus challenge. Our results reported here clearly indicate that in vitro refolded HA globular head could be used as a subtype-specific vaccine candidate and its application should be vigorously explored in the near future.

\section{RESULTS}

\section{Rational design of globular head constructs}

In the course of our efforts to solve the 2009-pandemic influenza HA structure (Zhang et al., 2010), a crystal with only the globular head of HA1 (clear electron density could be seen from amino acids 57-264) was obtained. This is presumably due to a cleavage/degradation during crystallization. Therefore we named this protein HA57-264 Baculo (Fig. 1) and started to design some new protein constructs for prokaryotic expression to simplify the protein preparation procedures for vaccine development. Based on this observation and the precise crystal structure of $\mathrm{HA}$, especially the $\mathrm{N}$ terminal part of HA1 interacting with $\mathrm{HA} 2$, we designed three globular head protein constructs which encompassed the neutralizing antibody epitopes of the globular head and also preserved its antigenic structure after recombinant protein expression in E. coli. The crystal structure-based globular head HA1 amino acid components were not considered in two recent HA head preparations (Khurana et al., 2010; DuBois et al., 2011a) while we were preparing our work. Therefore, we designed the first construct with a boundary placed at Ala57 of the N-terminus and Ala264 (HA57-264) of the C-terminus, to remove the HA1 N-terminal portion that interacts with HA2, and take the globular head crystal obtained unexpectedly into account as well (Fig. 1A). We also hypothesized that the disulfide bond between the second and sixth conserved cysteines of HA1 and a small $\beta$-sheet at residues $268-272$ 
A

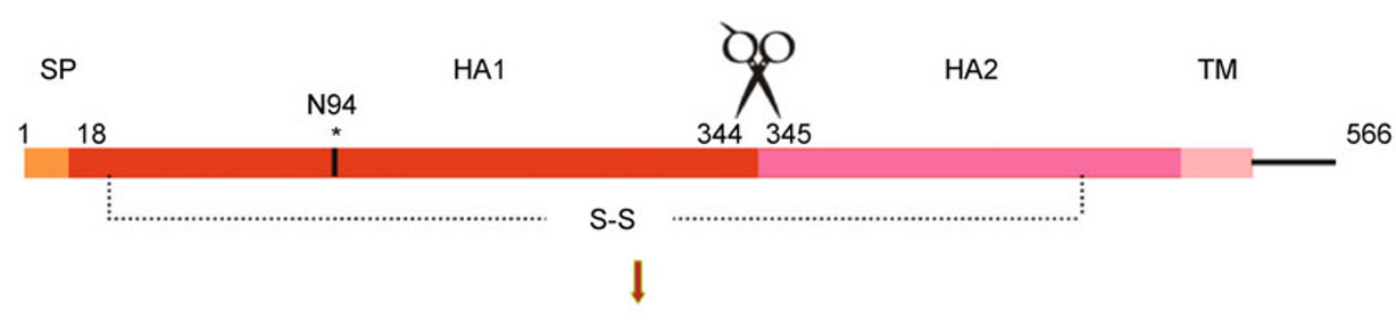

HA globular domain

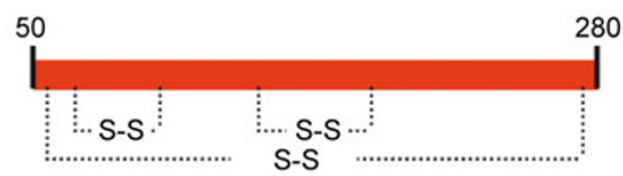

B

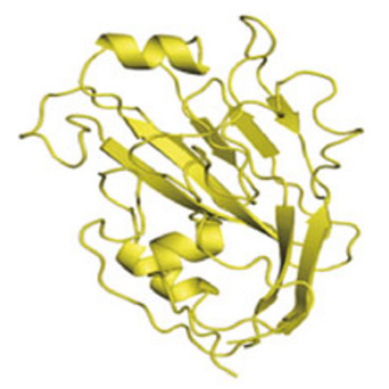

C

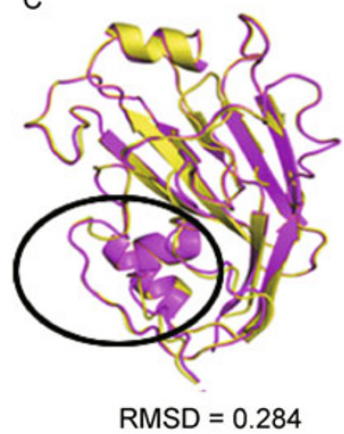

D

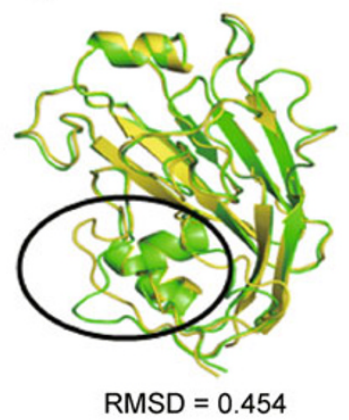

E

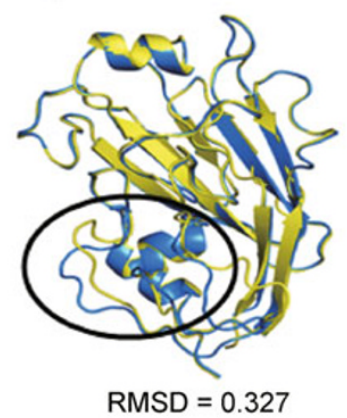

Figure 1. The E.coli expressed/refolded HA57-264 is also a typical hemagglutinin globular head fold. (A) Schematic representation of 2009-pandemic H1N1 hemagglutinin (HA). Numbers on the pictures represent the amino acid numbers of each motif. aa, amino acid; SP, signal peptide; TM, transmembrane region; Asn94 is a potential $\mathrm{N}$-glycosylation site. (B) Overall view of the

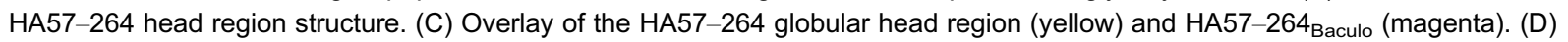
Overlay of the HA57-264 (yellow) and globular head domain from the full-length HA ectodomain (green). (E) Comparison of the monomers between HA57-264 and the published HA globular head structure (HA55-271). The RMSD values for all comparisons are very low, which shows that bacterially expressed H1N1 HA globular head could be properly refolded.

were important to further stabilize the globular head domain subunit. Therefore, we further designed two more constructs, HA57-272 and HA50-280, to evaluate the stabilization of the head domain by this disulfide bond. Clearly this is a versatile design by precisely considering the three dimensional crystal structure.

\section{HA head region is expressed in $E$. coli as an intact stable protein}

As described in the METHODS, DNA fragments encoding amino acids $57-264,57-272$ and $50-280$ of $\mathrm{HA}$ from $\mathrm{A} /$ California/04/2009 H1N1 influenza A virus were amplified and cloned into the pET21a vector under the control of a T7 promoter and the resultant proteins were named as HA57-264, HA57-272 and HA50-280, respectively. All fragments of HA globular heads were expressed in $E$. coli BL21 and induced using $1 \mathrm{mmol} / \mathrm{L}$ isopropyl- $\beta$-D-thiogalactopyranoside (IPTG) at $37^{\circ} \mathrm{C}$. The expressed proteins were in insoluble inclusion bodies which were solubilized with a buffer containing $6 \mathrm{~mol} / \mathrm{L}$ guanidine hydrochloride. Inclusion bodies were refolded in vitro under redox conditions and purified by gel filtration chromatography using a Hiload 16/60 Superdex$200 \mathrm{pg}$ column as monomeric form proteins judged by estimations of the molecular weight (MW) using gel-filtration elution volume (Fig. 2). All the three purified properly-refolded HA globular head proteins ran as a single band on SDSPAGE with the anticipated MWs of $24.1,25$ and $26.7 \mathrm{kDa}$, respectively (Fig. 2). The fragment of HA57-264 yielded higher quality and quantity protein than the other two constructs. Our results also indicate that the HA50-280 protein refolds properly with one extra disulfide bond. 


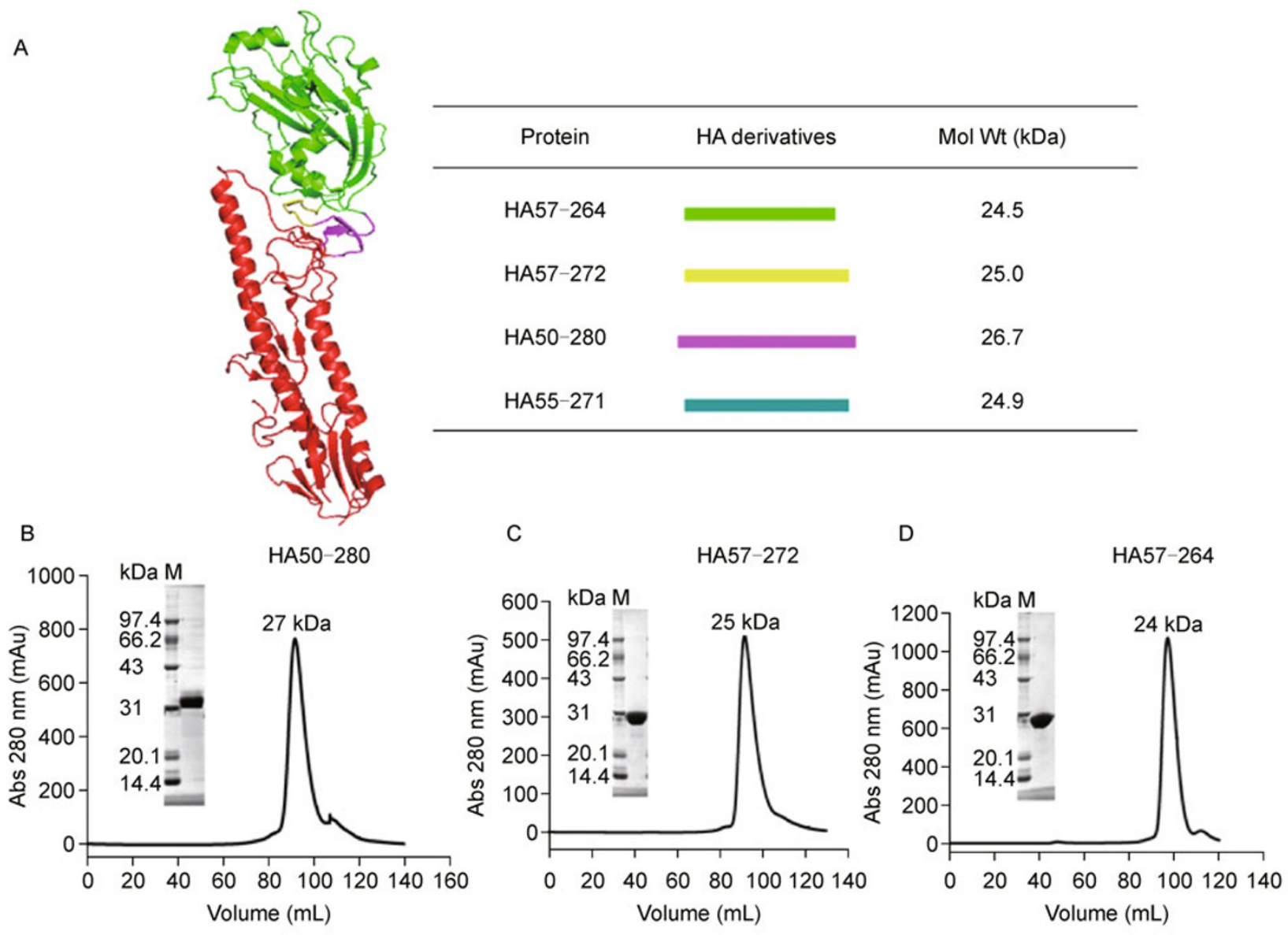

Figure 2. Rational design and biochemical analysis of the expressed proteins. (A) Characteristics of the designed proteins. Left panel shows a monomeric structure of the HA ectodomain addressing the HA globular head (green) and the stalk region (red). (B-D) The purified proteins were eluted as monomeric forms on a Hiload 16/60 Superdex-200 pg column and run as single bands at the expected molecular weight in reducing SDS-PAGE.

\section{Crystal structure analysis of the HA globular head domain}

Of the three HA globular head domains (HA57-264, HA57-272 and HA50-280) we prepared in this study, HA57-264 exhibits the best biophysical characters, making it of great interest to verify if the refolded HA57-264 retains the same globular structure as that seen in the $\mathrm{A} / \mathrm{H} 1 \mathrm{~N} 1 / 2009$ HA ectodomain structure generated by our baculovirus expression system (Zhang et al., 2010). The protein was successfully crystallized and the structure was solved by molecular replacement. As expected, HA57-264 adopts the same three-dimensional fold as the $\mathrm{A} / \mathrm{H} 1 \mathrm{~N} 1 / 2009 \mathrm{HA}$ ectodomain structure (Fig. 1B). We also compared this structure with that of the cleaved HA57-264 Baculo. Superimposition of these two HA globular head structures solved in this study yields an R.M.S.D of about $0.28 \AA$ (Fig. 1C), demonstrating that the structures are almost the same. Though there is a potential $N$-liked glycosylation site at N94, the HA57-264 $4_{\text {Baculo }}$ structure does not show clear electron density for any glycans.

In light of a previously reported $\mathrm{HA}$ full ectodomain structure, we further compared HA57-264 with the full-length HA protein for the expected structural conservation. Superimposition of these two structures resulted in an R.M.S.D of about 0.45 (Fig. 1D), with the only limited difference lying at the flexible bottom of the globular domain. This provides solid structural evidence that the $E$. coli expressed/refolded HA globular head was the same fold as that of baculovirusyielded full-ectodomain HA protein or HA57-264 Baculo, which $_{\text {, }}$ in turn supports our initial design strategy.

Meanwhile, one paper about the structure of bacterially expressed $\mathrm{H} 1 \mathrm{~N} 1 \mathrm{HA}$ globular head (amino acids 55-271) was published (DuBois et al., 2011a). Therefore, we also compared these two globular head structures (R.M.S.D = 0.33), and found that the main structure discrepancies are still on the flexible bottom of the globular head (Fig. 1E).

To develop subunit vaccines, we further studied the 


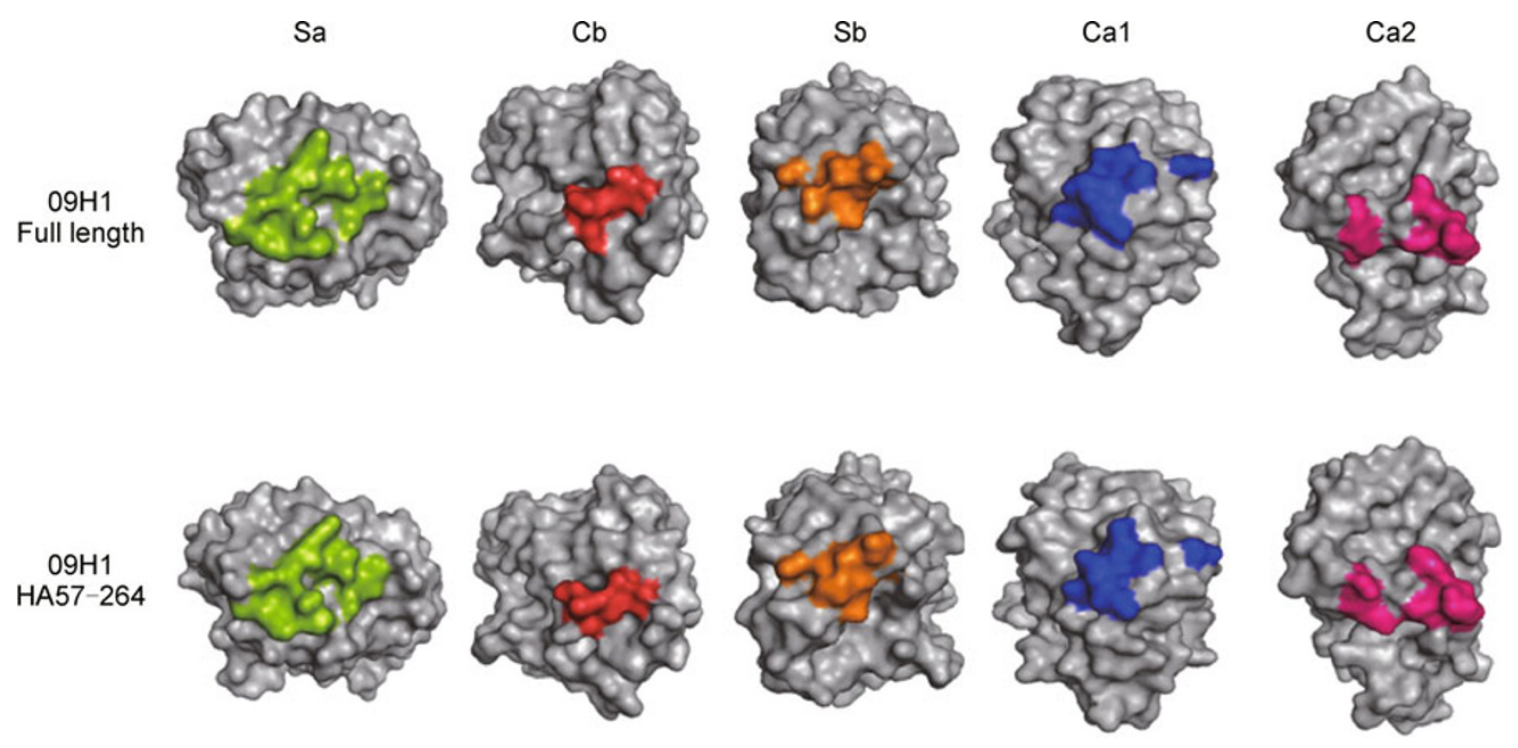

Figure 3. Highlight of the five defined antigenic sites (Sa, Sb, $\mathrm{Ca} 1, \mathrm{Ca} 2$ and $\mathrm{Cb}$ ) of the HA57-264 in comparison with the intact A/H1N1/2009 ectodomain structure. Almost the same conformations are observed on these two structures. All pictures were generated by PYMOL.

structure of HA57-264 for the defined antibody-recognizing sites ( $\mathrm{Sa}, \mathrm{Sb}, \mathrm{Ca} 1, \mathrm{Ca} 2$ and $\mathrm{Cb}$ ) (Caton et al., 1982; Igarashi et al., 2010; Sun et al., 2010; Zhang et al., 2010), which is important for the stimulation of immune response against the influenza virus. We compared these five antigenic sites with the intact $\mathrm{A} / \mathrm{H} 1 \mathrm{~N} 1 / 2009$ ectodomain structure, and found that they have almost the same conformations (Fig. 3). Therefore, the antigenic sites in the HA globular head are also structurally conserved between the refolded protein and the insect-cell expressed protein. This structural conservation indicates that the refolded HA57-264 protein does not lose its antigenicity and should be well able to stimulate an antibodyrelated immune response.

\section{Immunization and challenge studies in mice}

The protective immunity elicited by the bacterially expressed proteins was further evaluated in a mouse challenge model. Four-to-six weeks old female BALB/c mice $(n=8$ in each group) were immunized intramuscularly with HA57-264 at 25 $\mu \mathrm{g}$ or $50 \mu \mathrm{g}$ dose of immunogen along with complete Freund's adjuvant at a 1:1 ratio, and then boosted on day 28 with the same immunogen in incomplete Freund's adjuvant.

Serum samples were collected before the virus challenge and hemagglutination inhibition (HAl) was analyzed. As shown in Fig. 4, the HAl geometric mean titers (GMT) following two immunizations with HA57-264 were 1:235 $(1: 128-1: 512)$ and $1: 470(1: 256-1: 1024)$ at the $25 \mu \mathrm{g}$ dose level and $50 \mu \mathrm{g}$ dose level, respectively.

Following the second immunization, mice were challenged intranasally with $10^{6} 50 \%$ egg infectious doses $\left(E D_{50}\right)$ of $A /$ California/07/2009 virus in a volume of $50 \mu \mathrm{L}$. Weight loss was monitored twice a day up to day 7 after the challenge (Fig. 5). Mice immunized with $50 \mu \mathrm{g}$ HA57-264 lost about 8\% of their initial body weights in the first two days post-challenge but quickly regained their weights after day 6 post-infection (Fig. 5). The $25 \mu$ dose group lost $10 \%$ of their initial body weights by day 3 after challenge and slowly regained their weights. In contrast, all mice in the control group significantly lost over $23 \%$ of their body weights and were frequently shivering, indicating that these mice suffered severe illness, and were thereof euthanatized. These results demonstrated that bacterially expressed HA57-264 proteins were properly folded and could induce protective immune responses against homologous 2009-pandemic H1N1 influenza virus challenge.

\section{DISCUSSION}

In this study we have successfully designed three HA1 globular head proteins, characterized their biochemical properties and tested their immunogenicity. We found that the designed constructs can produce correctly-folded proteins as predicted. Our design, which includes the removal of some N-terminal portions of the HA1 that interact with HA2, has advantages over the strategies from two recent publications about globular head designs based upon primary sequences which include some $\mathrm{N}$-terminal HA1 regions that interact with HA2 (Khurana et al., 2010; DuBois et al., 2011b). Intact domain expression of the $\mathrm{N}$-terminal-removed HA1 globular head also implies that this domain, as an independent functional and structural module, has been inserted into the fusion domain of the influenza virus HA precursor through the evolution of the virus as proposed earlier (DuBois et al., 


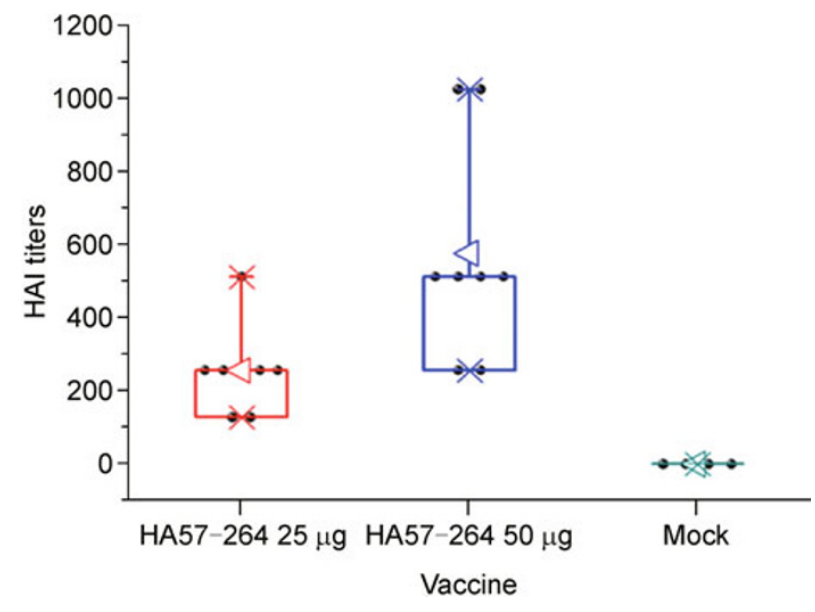

Figure 4. Protection against homologous 09 H1N1 influenza virus challenge. Groups of mice vaccinated with $25 \mu \mathrm{g}$ or $50 \mu \mathrm{g}$ of HA57-264 twice were challenged with $10^{6} \mathrm{EID}_{50} \mathrm{~A} /$ California/07/2009. Body weights were recorded twice a day for 7 days. $n=8$ mice per group. Mice were carefully observed throughout each day for signs of infection.

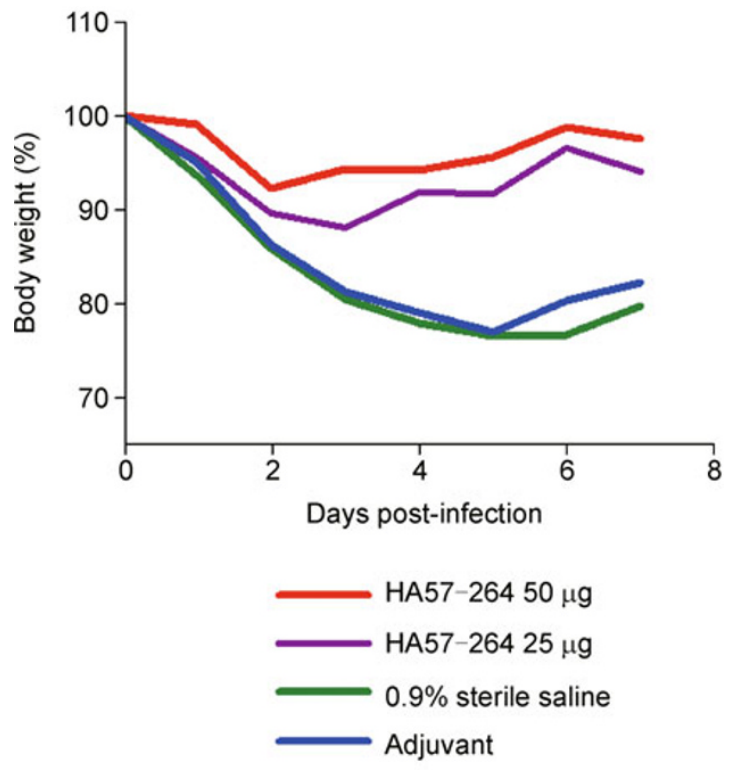

Figure 5. Hemagglutination inhibition (HAI) titers in mice. BALB/c mice were immunized intramuscularly with either $25 \mu \mathrm{g}$ or $50 \mu \mathrm{g}$ of HA57-264. Sera were collected before viral challenge and were assessed against A/California/07/2009. Bars indicate geometric mean titers (GMT). $n=8$ mice per group.

2011b). Immunogenicity experiment results have shown that the prepared proteins are highly immunogenic and can at least protect against homologous virus challenge. The $\mathrm{X}$-ray crystal structure of the HA57-264 has revealed that the five well-defined antigenic sites of $\mathrm{Sa}, \mathrm{Sb}, \mathrm{Ca} 1, \mathrm{Ca} 2$ and $\mathrm{Cb}$ are faithfully exposed in comparison to those in the trimer structures. Therefore the structural data support the immunogenicity results.

The successful refolding and solution of the crystal structure of HA57-264 have further shown that glycosylation sites are not necessary for HA globular head folding as the protein crystallized here has one potential $\mathrm{N}$-linked glycosylation site (Asn94) which was confirmed by our previous fulllength 2009-pandemic HA trimer structure (Zhang et al., 2010). In fact the unglycosylated protein has its own advantage for inducing a stronger antibody response as the sugar "cover" can mask the immune recognition in many enveloped viruses, including human immunodeficiency virus (HIV) (Vitale et al., 1991; Kubo et al., 2007). Therefore avoiding glycosylation is a good strategy to prepare a better vaccine.

Influenza pandemic is still a threat for human beings and the preparedness of any measures to conquer pandemics is in great need. Our experiments and others (Khurana et al., 2010; DuBois et al., 2011a; Khurana et al., 2011) have proved the concept that protein engineering of the receptor-binding globular head of HA is possible to produce novel subtypespecific subunit vaccines. In the future, other subtypes of influenza viruses should be tested and a multivalent vaccine including most of the subtypes that infect human beings should be designed to include formulated multi-components of HA globular head domains.

\section{MATERIALS AND METHODS}

\section{In silicon analysis of the HA structure}

Up to date, crystal structures of HAs from 7 out of 16 subtypes $(\mathrm{H} 1$, $\mathrm{H} 2, \mathrm{H} 3, \mathrm{H} 5, \mathrm{H} 7, \mathrm{H} 9$ and $\mathrm{H} 14$ ) have been solved (Wilson et al., 1981; Ha et al., 2002; Gamblin et al., 2004; Russell et al., 2004; Stevens et al., 2006; Russell et al., 2008; Xu et al., 2010; Zhang et al., 2010). All of them shared a similar three-dimensional fold (trimeric molecules), in which each monomer contains two disulfide-linked polypeptide chains, HA1 and HA2, generated by proteolytic cleavage of a single chain precursor, $\mathrm{HAO}$. The membrane-proximal stem of the trimer is composed of HA2 and two segments of HA1, residues 1-55 and 275-329, centered around a triple-stranded $\alpha$-helical coiled coil formed by the N-terminal half of the long central $\alpha$-helix of HA2. On top of the stem, the membrane-distal globular portion (residues 56-274) of the molecule contains the receptor binding subdomain and the vestigial esterase subdomain. All of the defined antibodyrecognizing sites ( $\mathrm{Sa}, \mathrm{Sb}, \mathrm{Ca} 1, \mathrm{Ca} 2$ and $\mathrm{Cb}$ ) (Caton et al., 1982) are located on the globular portion. Thus the globular portion of $\mathrm{HA}$ molecule should be sufficient to elicit the subtype-specific antibodymediated immune response as the intact trimeric HA molecule.

\section{Protein expression, refolding and purification}

The genes encoding the HA globular head domain (amino acids 57-264; 57-272; 50-280) of 2009-pandemic H1N1 influenza A virus HA (NCBI GenBank accession No. ACP41105) were respectively 
cloned into the $\mathrm{pET} 21$ a vector using the restriction sites of $E c o R \mathrm{I}$ and Xho I, with primer pairs of P1/P2, P3/P4 and P5/P6, respectively (P1, 5'-CGGAATTCATGGGGGTAGCCCCATTGC-3'; P2, 5'-CCGCTCGAGTTAAGCATTTCTTTCCATTGCGAATG-3'; P3, 5'-CGGAATTCATGGCCCCATTGCATTTGGGTAA-3'; P4, 5'-CCGCTCGAGTTATGTATCTGAAATGATAATACC-3'; P5, 5'-CGGAATTCATGGGGAAACTATGCAAACTAAGA-3'; P6, 5'-CCGCTCGAGTTAAGTTGTATTGCAATCGTGGAC-3'). The recombinant proteins were overexpressed in E. coli BL21 cells (Novagen) in inclusion bodies and the inclusion bodies were then dissolved in the denaturation buffer (50 mmol/L Tris, $100 \mathrm{mmol} / \mathrm{L} \mathrm{NaCl}, 10 \mathrm{mmol} / \mathrm{L}$ EDTA, $10 \mathrm{mmol} / \mathrm{L}$ DTT, $10 \%$ glycerol, $\mathrm{pH} 8.0$ ) containing $6 \mathrm{~mol} / \mathrm{L}$ guanidine hydrochloride with a final protein concentration of $30 \mathrm{mg} / \mathrm{mL}$. The proteins were slowly diluted in redox folding buffer containing $100 \mathrm{mmol} / \mathrm{L}$ Tris, $400 \mathrm{mmol} / \mathrm{L}$ L-arginine, $2 \mathrm{mmol} / \mathrm{L}$ EDTA, $5 \mathrm{mmol} / \mathrm{L}$ reduced glutathione and 1 $\mathrm{mmol} / \mathrm{L}$ oxidized glutathione, $\mathrm{pH} 8.0$, to promote refolding. Purified monomeric form proteins were purified by gel filtration chromatography using a Hiload 16/60 Superdex-200 pg column (GE Healthcare) with $20 \mathrm{mmol} / \mathrm{L}$ Tris- $\mathrm{HCl}$ and $150 \mathrm{mmol} / \mathrm{L} \mathrm{NaCl}, \mathrm{pH} 8.0$, as running buffer. For crystallization of the proteins, the proteins were in the buffer of $20 \mathrm{mmol} / \mathrm{L}$ Tris- $\mathrm{HCl}$ and $50 \mathrm{mmol} / \mathrm{L} \mathrm{NaCl}, \mathrm{pH} 8.0$.

\section{Crystallization, data collection and processing}

The HA57-264 $4_{\text {Baculo }}$ crystals were obtained in the course of crystallization of the full-length ectodomain $\mathrm{HA}$ as described earlier (Zhang et al., 2010). The HA globular head HA57-264 crystals were prepared using the hanging-drop vapor diffusion method at $18^{\circ} \mathrm{C}$ using Hampton Research kits for screening, with $1 \mu \mathrm{L}$ of protein solution combined with an equal volume of well solution. X-ray diffraction crystals grew in the condition of 20\% PEG3350, $0.2 \mathrm{~mol} / \mathrm{L}$ ammonium nitrate, $\mathrm{pH}$ 6.2. The crystals were soaked briefly in reservoir solutions containing protectent $17 \% \mathrm{~V} / \mathrm{V}$ glycerol, mounted on the $\mathrm{X}$-ray machine with a nylon loop, and flash-cooled in a stream of gaseous nitrogen. Diffraction data were collected using an in-house X-ray source (Rigaku MicroMax007 Desktop Rotating Anode X-Ray Generator with a $\mathrm{Cu}$ target operated at $40 \mathrm{kV}, 30 \mathrm{~mA}$ ) and R-AXIS IV++ imaging-plate detector at a wavelength of $1.5418 \AA$. Data were indexed, integrated and scaled using HKL2000 (Otwinowski and Minor, 1997).

\section{Structure determination, refinement and analysis}

The structures of HA57-264 and HA57-264 Baculo $_{\text {were solved at } 1.8}$ $\AA$ and $1.9 \AA$, respectively, by the molecular replacement method using Phaser (Read, 2001) from the CCP4 program suite (CCP4, 1994) (Collaborative Computational Project, Number 4) with the structure of 09H1 (PDB ID 3LYJ) as the search model. Extensive model building and restrained refinement were performed using COOT (Emsley and Cowtan, 2004) and REFMAC5 (Murshudov et al., 1997). The Further rounds of refinement were performed using the Phenixrefine program implemented in the PHENIX package (Adams et al., 2002) with coordinate refinement isotropic ADP refinement and bulk solvent modeling. The final models have an $R_{\text {work }}$ of 0.18 and an $R_{\text {free }}$ of 0.20 for HA57-264 $4_{\text {Baculo }}$ and an $R_{\text {work }}$ of 0.17 and an $R_{\text {free }}$ of 0.20 for HA57-264, respectively. The stereochemical quality of the final model was assessed with the program PROCHECK (Laskowski et al., 1993). The detailed statistics are summarized in Table 1.
Table 1 Data collection and refinement statistics

\begin{tabular}{|c|c|c|}
\hline & HA57-264 $4_{\text {Baculo }}$ & HA57-264 \\
\hline \multicolumn{3}{|l|}{ Data collection } \\
\hline Space group & P1 & $\mathrm{P} 2_{1}$ \\
\hline \multicolumn{3}{|l|}{ Cell dimensions } \\
\hline$a, b, c(\AA)$ & $38.67,65.92,79.49$ & $46.66,75.05,60.13$ \\
\hline$\alpha, \beta, \gamma\left({ }^{\circ}\right)$ & $94.46,89.97,94.88$ & $90.00,104.17,90.00$ \\
\hline Resolution $(\AA)$ & $\begin{array}{l}50.00-1.90 \\
(1.97-1.90)\end{array}$ & $\begin{array}{l}50.00-1.80 \\
(1.86-1.80)\end{array}$ \\
\hline$R_{\text {sym }}$ or $R_{\text {merge }}$ & $0.057(0.221)$ & $0.071(0.381)$ \\
\hline $\mid / \sigma /$ & $22.6(5.5)$ & $18.8(2.7)$ \\
\hline Completeness (\%) & $97.4(95.4)$ & $99.6(98.4)$ \\
\hline Redundancy & $3.9(3.7)$ & $3.6(3.3)$ \\
\hline
\end{tabular}

\section{Refinement}

Resolution $(\AA)$

$35.1-1.9$

19.7-1.8

No. reflections

58173

35962

$R_{\text {work }} / R_{\text {free }}$

$0.18 / 0.20$

$0.17 / 0.20$

No. atoms

Protein

Ligand/ion

6829

2

3430

Water

822

2

439

$B$-factors

Protein

Ligand/ion

27.4

23.4

Water

36.3

24.5

30.9

R.m.s. deviations

Bond lengths $(\AA)$

32.2

0.005

Bond angles $\left({ }^{\circ}\right)$

0.016

0.964

*Values in parentheses are for highest-resolution shell.

\section{Immunization of mice}

Four-to-six weeks old female BALB/c mice were immunized intramuscularly with $25 \mu \mathrm{g}$ or $50 \mu \mathrm{g}$ of immunogen HA57-264 along with Complete Freund's adjuvant (Sigma) at a 11 ratio, and then boosted four weeks later with the same immunogen in incomplete Freund's adjuvant. Control animals $(n=4)$ were mock vaccinated with $0.9 \%$ sterile saline in adjuvant. The volume for all intra-muscular vaccinations was $100 \mu \mathrm{L}$. At week 8 , the mice were intranasally challenged with $10^{6} \mathrm{EID}_{50}$ of A/California/07/2009 influenza $A$ virus in $50 \mu \mathrm{L}$, and their weights were monitored twice a day for seven days. Before virus infection, individual mouse was bled and sera were isolated by centrifugation of the blood samples.

\section{HAl assay}

A HAl assay was carried out according to standard methods (Meijer et al., 2006). Sera were two-fold diluted in v-bottom 96-well microtiter plates, and then $4 \mathrm{HA}$ units of $\mathrm{A} / \mathrm{California/07/2009}$ influenza $\mathrm{A}$ virus were added. After approximately $30 \mathrm{~min}$ incubation at room temperature, $1 \%$ chicken red blood cells (RBCs) suspension was added and 
incubated for $30 \mathrm{~min}$ at room temperature. HAl titers of the sera were determined based on the highest serum dilution at which hemagglutination was completely inhibited.

\section{ACKNOWLEDGEMENTS}

This work was supported by the National Basic Research Program (973 Program) (Grant No. 2011CB504703). We are grateful to Dr Christopher Vavricka and Dr Guangwen Lu for their help. GFG is a leading principal investigator of the Innovative Research Group of the National Natural Science Foundation of China (Grant No. 81021003).

Atomic coordinates and structure factors for the reported crystal structures have been deposited into the Protein Data Bank with accession numbers $3 U Y W$ for HA57-264 $4_{\text {Bacolo }}$ and $3 U Y X$ for HA57-264, respectively.

\section{ABBREVIATIONS}

$\mathrm{HA}$, hemagglutinin; HAl, hemagglutination inhibition; HIV, human immunodeficiency virus; NA, neuraminidase

\section{REFERENCES}

Adams, P.D., Grosse-Kunstleve, R.W., Hung, L.W., loerger, T.R., McCoy, A.J., Moriarty, N.W., Read, R.J., Sacchettini, J.C., Sauter, N.K., and Terwilliger, T.C. (2002). PHENIX: building new software for automated crystallographic structure determination. Acta Crystallogr D Biol Crystallogr 58, 1948-1954.

Beigel, J.H., Farrar, J., Han, A.M., Hayden, F.G., Hyer, R., de Jong, M. D., Lochindarat, S., Nguyen, T.K., Nguyen, T.H., Tran, T.H., et al., and the Writing Committee of the World Health Organization (WHO) Consultation on Human Influenza A/H5. (2005). Avian influenza A (H5N1) infection in humans. N Engl J Med 353, 1374-1385.

Belser, J.A., Lu, X., Maines, T.R., Smith, C., Li, Y., Donis, R.O., Katz, J.M., and Tumpey, T.M. (2007). Pathogenesis of avian influenza $(\mathrm{H} 7)$ virus infection in mice and ferrets: enhanced virulence of Eurasian H7N7 viruses isolated from humans. J Virol 81, 11139-11147.

Belshe, R.B., Gruber, W.C., Mendelman, P.M., Cho, I., Reisinger, K., Block, S.L., Wittes, J., lacuzio, D., Piedra, P., Treanor, J., et al. (2000). Efficacy of vaccination with live attenuated, cold-adapted, trivalent, intranasal influenza virus vaccine against a variant $(A /$ Sydney) not contained in the vaccine. J Pediatr 136, 168-175.

Bommakanti, G., Citron, M.P., Hepler, R.W., Callahan, C., Heidecker, G.J., Najar, T.A., Lu, X., Joyce, J.G., Shiver, J.W., Casimiro, D.R., et al. (2010). Design of an HA2-based Escherichia coli expressed influenza immunogen that protects mice from pathogenic challenge. Proc Natl Acad Sci U S A 107, 13701-13706.

Caton, A.J., Brownlee, G.G., Yewdell, J.W., and Gerhard, W. (1982). The antigenic structure of the influenza virus A/PR/8/34 hemagglutinin ( $\mathrm{H} 1$ subtype). Cell 31, 417-427.

Claas, E.C., Osterhaus, A.D., van Beek, R., De Jong, J.C., Rimmelzwaan, G.F., Senne, D.A., Krauss, S., Shortridge, K.F., and Webster, R.G. (1998). Human influenza A H5N1 virus related to a highly pathogenic avian influenza virus. Lancet 351 , 472-477.

Collaborative Computational Project, Number 4. (1994). The CCP4 suite: programs for protein crystallography. Acta Crystallogr D Biol Crystallogr 50, 760-763.

Corti, D., Voss, J., Gamblin, S.J., Codoni, G., Macagno, A., Jarrossay, D., Vachieri, S.G., Pinna, D., Minola, A., Vanzetta, F., et al. (2011). A neutralizing antibody selected from plasma cells that binds to group 1 and group 2 influenza A hemagglutinins. Science 333, 850-856.

Das, K., Aramini, J.M., Ma, L.C., Krug, R.M., and Arnold, E. (2010). Structures of influenza A proteins and insights into antiviral drug targets. Nat Struct Mol Biol 17, 530-538.

DuBois, R.M., Aguilar-Yañez, J.M., Mendoza-Ochoa, G.I., OropezaAlmazán, Y., Schultz-Cherry, S., Alvarez, M.M., White, S.W., and Russell, C.J. (2011a). The receptor-binding domain of influenza virus hemagglutinin produced in Escherichia coli folds into its native, immunogenic structure. J Virol 85, 865-872.

DuBois, R.M., Aguilar-Yañez, J.M., Mendoza-Ochoa, G.I., OropezaAlmazán, Y., Schultz-Cherry, S., Alvarez, M.M., White, S.W., and Russell, C.J. (2011b). The receptor-binding domain of influenza virus hemagglutinin produced in Escherichia coli folds into its native, immunogenic structure. J Virol 85, 865-872.

Ekiert, D.C., Bhabha, G., Elsliger, M.A., Friesen, R.H., Jongeneelen, M., Throsby, M., Goudsmit, J., and Wilson, I.A. (2009). Antibody recognition of a highly conserved influenza virus epitope. Science 324, 246-251.

Ekiert, D.C., Friesen, R.H., Bhabha, G., Kwaks, T., Jongeneelen, M., Yu, W., Ophorst, C., Cox, F., Korse, H.J., Brandenburg, B., et al. (2011). A highly conserved neutralizing epitope on group 2 influenza A viruses. Science 333, 843-850.

Emsley, P., and Cowtan, K. (2004). Coot: model-building tools for molecular graphics. Acta Crystallogr D Biol Crystallogr 60, 2126-2132.

Fields, B.N., Knipe, D.M., and Howley, P.M. (2007). Fields virology, 5th ed. Philadelphia: Wolters Kluwer Health/Lippincott Williams \& Wilkins.

Furuya, Y., Regner, M., Lobigs, M., Koskinen, A., Müllbacher, A., and Alsharifi, M. (2010). Effect of inactivation method on the crossprotective immunity induced by whole 'killed' influenza A viruses and commercial vaccine preparations. J Gen Virol 91, 1450-1460.

Gamblin, S.J., Haire, L.F., Russell, R.J., Stevens, D.J., Xiao, B., Ha, Y., Vasisht, N., Steinhauer, D.A., Daniels, R.S., Elliot, A., et al. (2004). The structure and receptor binding properties of the 1918 influenza hemagglutinin. Science 303, 1838-1842.

Guan, Y., Vijaykrishna, D., Bahl, J., Zhu, H., Wang, J., and Smith, G.J. (2010). The emergence of pandemic influenza viruses. Protein Cell 1, 9-13.

Ha, Y., Stevens, D.J., Skehel, J.J., and Wiley, D.C. (2002). H5 avian and $\mathrm{H} 9$ swine influenza virus haemagglutinin structures: possible origin of influenza subtypes. EMBO J 21, 865-875.

Igarashi, M., Ito, K., Yoshida, R., Tomabechi, D., Kida, H., and Takada, A. (2010). Predicting the antigenic structure of the pandemic (H1N1) 2009 influenza virus hemagglutinin. PLoS One 5, e8553.

Khurana, S., Larkin, C., Verma, S., Joshi, M.B., Fontana, J., Steven, A.C., King, L.R., Manischewitz, J., McCormick, W., Gupta, R.K., et al. (2011). Recombinant HA1 produced in E. coli forms functional oligomers and generates strain-specific SRID potency antibodies for pandemic influenza vaccines. Vaccine 29, 5657-5665.

Khurana, S., Verma, S., Verma, N., Crevar, C.J., Carter, D.M., 
Manischewitz, J., King, L.R., Ross, T.M., and Golding, H. (2010). Properly folded bacterially expressed H1N1 hemagglutinin globular head and ectodomain vaccines protect ferrets against H1N1 pandemic influenza virus. PLoS One 5, e11548.

Kilbourne, E.D. (2006). Influenza pandemics of the 20th century. Emerg Infect Dis 12, 9-14.

Kubo, Y., Yokoyama, M., Yoshii, H., Mitani, C., Tominaga, C., Tanaka, Y., Sato, H., and Yamamoto, N. (2007). Inhibitory role of CXCR4 glycan in CD4-independent $\mathrm{X} 4$-tropic human immunodeficiency virus type 1 infection and its abrogation in CD4-dependent infection. J Gen Virol 88, 3139-3144.

Kurtz, J., Manvell, R.J., and Banks, J. (1996). Avian influenza virus isolated from a woman with conjunctivitis. Lancet 348, 901-902.

Laskowski, R.A., MacArthur, M.W., Moss, D.S., and Thornton, J.M. (1993). PROCHECK: A program to check the stereochemical quality of protein structures. J Appl Cryst 26, 283-291.

Lin, Y.P., Shaw, M., Gregory, V., Cameron, K., Lim, W., Klimov, A., Subbarao, K., Guan, Y., Krauss, S., Shortridge, K., et al. (2000). Avian-to-human transmission of H9N2 subtype influenza A viruses: relationship between $\mathrm{H} 9 \mathrm{~N} 2$ and $\mathrm{H} 5 \mathrm{~N} 1$ human isolates. Proc Natl Acad Sci U S A 97, 9654-9658.

Lipsitch, M., Cohen, T., Murray, M., and Levin, B.R. (2007). Antiviral resistance and the control of pandemic influenza. PLoS Med 4, e15.

Meijer, A., Bosman, A., van de Kamp, E.E.H.M., Wilbrink, B., Du Ry van Beest Holle, M., and Koopmans, M. (2006). Measurement of antibodies to avian influenza virus $A(H 7 N 7)$ in humans by hemagglutination inhibition test. J Virol Methods 132, 113-120.

Murshudov, G.N., Vagin, A.A., and Dodson, E.J. (1997). Refinement of macromolecular structures by the maximum-likelihood method. Acta Crystallogr D Biol Crystallogr 53, 240-255.

Neumann, G., Noda, T., and Kawaoka, Y. (2009). Emergence and pandemic potential of swine-origin H1N1 influenza virus. Nature 459, 931-939.

Otwinowski, Z., and Minor, W. (1997). Processing of X-ray diffraction data collected in oscillation mode. Methods Enzymol 276, 307-326.

Read, R.J. (2001). Pushing the boundaries of molecular replacement with maximum likelihood. Acta Crystallogr D Biol Crystallogr 57, 1373-1382.

Russell, R.J., Gamblin, S.J., Haire, L.F., Stevens, D.J., Xiao, B., Ha, Y., and Skehel, J.J. (2004). H1 and H7 influenza haemagglutinin structures extend a structural classification of haemagglutinin subtypes. Virology 325, 287-296.

Russell, R.J., Kerry, P.S., Stevens, D.J., Steinhauer, D.A., Martin, S. R., Gamblin, S.J., and Skehel, J.J. (2008). Structure of influenza hemagglutinin in complex with an inhibitor of membrane fusion. Proc Natl Acad Sci U S A 105, 17736-17741.

Skehel, J.J., and Wiley, D.C. (2000). Receptor binding and membrane fusion in virus entry: the influenza hemagglutinin. Annu Rev Biochem 69, 531-569.
Stevens, J., Blixt, O., Tumpey, T.M., Taubenberger, J.K., Paulson, J. C., and Wilson, I.A. (2006). Structure and receptor specificity of the hemagglutinin from an H5N1 influenza virus. Science 312 , 404-410.

Subbarao, K., Klimov, A., Katz, J., Regnery, H., Lim, W., Hall, H., Perdue, M., Swayne, D., Bender, C., Huang, J., et al. (1998). Characterization of an avian influenza A (H5N1) virus isolated from a child with a fatal respiratory illness. Science 279, 393-396.

Sun, Y., Shi, Y., Zhang, W., Li, Q., Liu, D., Vavricka, C., Yan, J., and Gao, G.F. (2010). In silico characterization of the functional and structural modules of the hemagglutinin protein from the swineorigin influenza virus A (H1N1)-2009. Sci China Life Sci 53, 633-642.

Tran, T.H., Nguyen, T.L., Nguyen, T.D., Luong, T.S., Pham, P.M., Nguyen, V.C., Pham, T.S., Vo, C.D., Le, T.Q., Ngo, T.T., et al., and the World Health Organization International Avian Influenza Investigative Team. (2004). Avian influenza A (H5N1) in 10 patients in Vietnam. N Engl J Med 350, 1179-1188.

Vavricka, C.J., Li, Q., Wu, Y., Qi, J., Wang, M., Liu, Y., Gao, F., Liu, J., Feng, E., He, J., et al. (2011). Structural and functional analysis of laninamivir and its octanoate prodrug reveals group specific mechanisms for influenza NA inhibition. PLoS Pathog 7, e1002249.

Vitale, F., Russo Alesi, D., Bonura, F., Di Benedetto, M.A., Mammina, C., and Romano, N. (1991). Change in size of the envelope glycoprotein of a human immunodeficiency virus 1 (HIV 1) strain. Microbiologica 14, 15-20.

Wang, T.T., Tan, G.S., Hai, R., Pica, N., Ngai, L., Ekiert, D.C., Wilson, I.A., García-Sastre, A., Moran, T.M., and Palese, P. (2010). Vaccination with a synthetic peptide from the influenza virus hemagglutinin provides protection against distinct viral subtypes. Proc Natl Acad Sci U S A 107, 18979-18984.

Wilson, I.A., Skehel, J.J., and Wiley, D.C. (1981). Structure of the haemagglutinin membrane glycoprotein of influenza virus at $3 \mathrm{~A}$ resolution. Nature 289, 366-373.

Wood, J.M., and Robertson, J.S. (2004). From lethal virus to lifesaving vaccine: developing inactivated vaccines for pandemic influenza. Nat Rev Microbiol 2, 842-847.

Xu, R., McBride, R., Paulson, J.C., Basler, C.F., and Wilson, I.A. (2010). Structure, receptor binding, and antigenicity of influenza virus hemagglutinins from the $1957 \mathrm{H} 2 \mathrm{~N} 2$ pandemic. J Virol 84, 1715-1721.

Yang, Y., Sugimoto, J.D., Halloran, M.E., Basta, N.E., Chao, D.L., Matrajt, L., Potter, G., Kenah, E., and Longini, I.M. Jr. (2009). The transmissibility and control of pandemic influenza A (H1N1) virus. Science 326, 729-733.

Zhang, W., Qi, J., Shi, Y., Li, Q., Gao, F., Sun, Y., Lu, X., Lu, Q., Vavricka, C.J., Liu, D., et al. (2010). Crystal structure of the swineorigin A (H1N1)-2009 influenza A virus hemagglutinin (HA) reveals similar antigenicity to that of the 1918 pandemic virus. Protein Cell $1,459-467$. 